\title{
Changes in Student Perceptions of Engineering Design During the Comple- tion of a Solid Modeling Course
}

\section{Dr. Steven Joseph Kirstukas, Central Connecticut State University}

Steve Kirstukas is an Assistant Professor at CCSU, where he teaches courses in solid modeling, MAT$\mathrm{LAB}$ programming, and engineering mechanics. He is exploring the use of virtual reality to enhance the engineering design process. He has degrees in civil and mechanical engineering, with a Ph.D. from the University of Minnesota. Steve has worked in industry as a civil engineer, software developer, biomechanics researcher, and mechanical design engineer.

\section{Nidal Al-Masoud, Central Connecticut State University}

Dr. Al-Masoud, Associate Professor, earned his Ph.D. in Mechanical Engineering from University at Buffalo, The State University of New York in 2002. Dr. Al-Masoud has taught at both graduate and undergraduate level courses at University at Buffalo, he joined Central Connecticut State University as an Assistant Professor in 2003. At CCSU, he teaches courses at all levels in the three major areas in mechanical engineering, namely: mechanics, Thermo-fluid, and Control Systems and Dynamics. Dr. Al-Masoud research interests are in the fields of Control Systems and Dynamics, HVAC systems, and Engineering Education. He has numerous journal and conference proceeding publications in the aforementioned area, and was the winner of the ASEE Mechanics Division Best paper Award in 2006. He has an extensive experience in Heating Ventilation and Air Conditioning Systems (HVAC) design. 


\title{
Changes in Student Perceptions of Engineering Design During the Completion of a Solid Modeling Course
}

\begin{abstract}
For several years, we have used evaluations of students' work in a solid modeling course as part of an assessment and evaluation method for ABET learning outcomes $\mathrm{C}$ and $\mathrm{K}$; the ability of students to design a system, component, or process, and to use modern engineering tools necessary for successful engineering practice. The evaluation process focuses on the students' ability to apply a specific software package (NX, formerly known as Unigraphics) in a sophomore-level course entitled "Computer Aided Design and Integrated Manufacturing CAD/CAM/CIM" where they work on assignments and a self-selected project that involve using the software efficiently, creating the correct geometry in both shape and size, and employing constraint-based solid modeling to transfer design intent from drawing to model. The creation of part models, assemblies, and layout drawings is covered. While it is clear and measurable that students come a long way towards mastering these concepts, what we have not known is how their perceptions of engineering design have changed during the semester in which they completed the solid modeling course. In this study, we follow a cohort of students through a fifteen-week solid modeling course. The identical web-based survey is administered during the first week and after the fifteenth week of classes. The survey is composed of several open-ended and multiple-choice questions that ask students what they feel are important attributes in solid modeling and engineering design. Our goal is the development and refinement of a tool that can measure the progress of students as their understanding of engineering design evolves from a relatively immature state to a more advanced understanding.
\end{abstract}

\section{Introduction}

Since the inception of the mechanical engineering program in 2006, the Department of Engineering at Central State Connecticut University has maintained a comprehensive Student Learning Outcomes (SLO) assessment process and evaluation. Several direct and indirect measures have been used throughout the process. Direct measures include regular exams and quizzes designed to test the mastery of specific skills, fundamentals of engineering (FE) style exams, computer projects, and lab or project reports. Indirect measures include the exit interview, and input from focus groups and Industrial Advisory Board members.

ABET's Engineering Accreditation Commission (ABET/EAC) requires that engineering programs demonstrate that their graduates meet eleven basic outcomes ${ }^{1}$ (although individual programs are free to define additional program-specific outcomes). The outcomes are typically listed using lower case letters. This paper concerns the two outcomes, c and k, utilizing the mastery of solid modeling packages as an assessment tool. For these two outcomes, ABET requires that students graduate with:

(c) an ability to design a system, component, or process to meet desired needs within realistic constraints such as economic, environmental, social, political, ethical, health and safety, manufacturability, and sustainability. 
(k) an ability to use the techniques, skills, and modern engineering tools necessary for engineering practice.

In general, student learning outcome c focuses on the ability of students to follow the logical and orderly design procedures that can be manifested in the following statements:

1. Problem or opportunity identification supported by factual evidence.

2. Creation of an executable design strategy including timetable, critical path, major tasks, subtasks and their interaction.

3. Creation of clear vision of expectation and deliverables with the available resources and constraints such as economic, environmental, social, policies and legal, ethical, health and safety, manufacturability, and sustainability

4. Testing and evaluation of the product and the process against the set goals and or performance criteria.

In relation to solid modeling, student learning outcome k focuses, among other tools, on the ability of students to use specialized engineering software ${ }^{2}$ :

1. in classroom work guided by the instructor.

2. in assignments without help of the instructor.

3. in design projects where students make an appropriate choice of the tool. Projects are evaluated on efficient use of the software, expression of correct geometry, and capturing design intent.

Our mechanical engineering and mechanical engineering technology programs use student data from a sophomore level class where solid modeling is a primary component to assess and measure our students' performance particularly for the use of software packages for product development. Although one might think it is premature to talk about the concept of design at the sophomore level, however, our objective is mainly to foster the design mentality, creativity, logical and systematic thinking in students as early as possible in their academic career. We believe that such an initiative is quite beneficial for students as they advance further, and develop into practicing engineers.

Another important aspect is that exposing students to such exercises would be very helpful in identifying the strengths and weaknesses and to address any shortcomings in a timely manner. The outlined procedure is based on a class called "Computer Aided Design and Integrated Manufacturing CAD/CAM/CIM.” This class uses the Siemens NX (formerly Unigraphics) software package to construct solid models. From our catalog description, the course is an "Introduction to solid modeling for design, drawing, assembly, mass property analysis and manufacturing operations on a CAD/CAM/CIM system. Emphasis is on computer hardware utilization for designing products.” It is important to note that the use of a particular software platform has no significance; the principle applies to any platform.

Although Mechanical Engineering and Engineering Technology students are initiated in the essential pieces of the engineering design process as part of their first semester Introduction to Engineering course, students are not really ready for the full iterative design process until they have had all the fundamental math and physics courses and have completed Machine Design. 
Thus for a full-time student on a fast path, they would be ready for engineering design at the end of the third year. At our school, many students are juggling part-time or even full-time careers and their coursework goes at a slower pace. In these cases, there could be five or more years before a student could fully participate in the engineering design process. Students who matriculate with weak mathematical backgrounds face similarly long roads as they first need to strengthen their mathematical foundation before moving into the engineering curriculum.

The solid modeling courses provide a unique opportunity to work with many of the core components of the engineering design process much earlier in the curriculum. For instance, the development of a solid model of a complex part requires identifying criteria (such as necessary dimensions), brainstorming, generating ideas, developing a plan to produce the solid model in an efficient manner, and actually constructing the solid model. Additionally, there can be some iterations in the plan as the designer attempts to develop a creation path and runs into an obstacle and has to revise the plan.

Unlike full-scale engineering design, Mathematics and Physics are not obstacles in the design process involved with the creation of 3D solid models. First, Physics is not really an issue as we are not concerned with mass, acceleration, or forces. Second, the way we teach solid modeling, with an emphasis on the creation of simple changeable models, actually discourages math in the modeling process. If the original 2D drawing is dimensionally complete, the goal of the 3D solid modeler is to construct a model using the dimensions on the drawing, no more or no less. This is possible through the application of geometric constraints, such as the midpoint constraint to center features on part faces. In the rare cases where math may be needed, such as in specifying the angular spacing of a pattern of five holes in a circle, the angular spacing between holes would be 360/5 = 72 degrees. If the student needs to enter the angular spacing, they are encouraged to enter 360/5 (rather than the equivalent 72) and "let NX do the math". As such, the math background needed for solid modeling is extremely low. In fact, ETM 260 has no prerequisites at all.

\section{Methods}

Mosborg has used a survey ${ }^{3}$ to evaluate perceptions of engineering design of advanced practicing engineering professionals in the mechanical, electrical, civil engineers, industrial, material sciences, and systems engineering fields. Mosborg listed 27 statements regarding the definition of design and had the raters rate the statements on a five-point scale from "Strongly Disagree" to "Strongly Agree". To understand the perceived value of different design activities, Mosborg listed 23 design activities and asked the raters to identify the six most important and six least important activities. Oehlberg ${ }^{4}$ did a very similar survey and added a $24^{\text {th }}$ activity, “Understanding others' point of view”.

Based on Mosborg's work, a two-page web survey was developed (Appendix A) using the tools available at surveyMonkey.com ${ }^{5}$. Except for one optional question, all survey questions were required to be fully answered. This was accomplished through error checking features of the web-based software program. User interface elements such as radio buttons insured that only one response could be selected for each particular item. 
In order to focus specifically on the modeling aspect of design and to create a simpler survey, we reduced its complexity. We edited Mosborg's original design definition list down to the 9 statements and shortened Mosborg's original activity list down to the 19 activities we felt most pertinent to Solid Modeling. Based on student input from a previous survey ${ }^{6}$, we added a $20^{\text {th }}$ solid modeling activity: managing time. By keeping the number of items as low as practicable, we shortened the time to complete the survey, reduced survey fatigue, and allowed multi-item questions to fit in a single screen view on a computer display. For instance, of Mosborg's original list of design activities, we eliminated prototyping, seeking information, synthesizing, and understanding the problem. These four activities can be very important in a general design discussion, but arguably less important when the issue involves creating a 3D solid model of known geometry.

There are numerous variations of the definition of engineering design ${ }^{7-11}$. Because there is no universally accepted definition of engineering design, the following definition ${ }^{12}$ is used in this study:

"The engineering designing process is one of working with others to solve complex, open-ended, and often ill-structured problems, and to synthesize a specification of the function, form, behaviour, performance, manufacture, operation, maintenance, and disposal of a technological artifact (an element, system, or process), such that the artifact's use promotes a preferred situation addressing identifiable objectives and constraints in a given technological, environmental, health and safety, economic, corporate, societal, political, and cultural context”

Rather than have the students select multiple-choice responses regarding engineering design, we asked an open-ended question and then rated their responses in accordance with the above definition. A single rater then judged the response on a four-point scale, with $4=$ excellent, $3=$ very good, 2 = satisfactory, and 1 = poor.

The survey was created as an optional assignment in the Moodle Course Management System ${ }^{13}$. The identical assignment appeared twice: in the first week of class and in the fifteenth week of class. The survey assignment was an optional assignment but students would receive one point bonus to their final grade as a reward for participation. Students only got the bonus if they completed both surveys. Because our school uses a plus-minus grade scale, with each grade category spanning three or four points, the one point bonus would result in an increase of the final letter grade for about one-third of the participating students. The survey deadline was prior to the grading of the final exam. Thus no students could know for sure whether the bonus would affect their final grade.

\section{Results}

There were 36 students enrolled in two sections of ETM 260 at the end of the course in Spring 2012. Of the 36, two students had not officially withdrawn but had discontinued attendance, did not submit the self-selected project, and did not take the final exam. Of the 34 active students in the course at the end of the course, 26 students completed the week 1 survey and 29 students completed the week 15 survey. Because we were interested in perception changes of a small group of students, we retained only the surveys for those who completed both the week 1 and week 15 surveys. A total of 22 students completed both parts of the survey for a $65 \%$ survey 
response rate. Because of the integrated error checking, all surveys were complete and thus the survey completion rate was also $65 \%$.

Survey item 2: In your own words, how do you define engineering design? The objective of this question was both to explore the mindset of student about the concept of design and at the same time to jump-start the thinking process about the attributes of the designer in general. An empty text box was available to receive short answers in the student's own words. An answer was required, although some students discovered that any amount of text would satisfy the error check. As such, there were a number of non-useful responses, such as "creative”, or "very interesting”.

The most common useful response involved the creation of a simulation model and/or a physical part or product, with emphasis on the concept of creation. Representative responses included "Creating a plan to aid in the design of a product", "designing equipment or machines for people to use”, and "engineering design turns ideas into reality by design and help manufacture of new parts”.

The second most common set of definitions involved brainstorming, generating ideas and alternatives, and problem solving, with emphasis on the thought processes involved with creating or improving products. Representative responses included "Engineering design is the process of taking your creativity and imagination as well as your knowledge in the specific field of engineering to create a solution to a problem”.

The third and final set of definitions involved visual communication of the quantitative features of a part or assembly of parts, with emphasis on the concept of communication. Representative responses included "Engineering design is meeting certain specifications so that someone can make a part by viewing your sketches, models, and drawings", and "engineering design is the use of computer aided designing programs to create 3 dimensional images of items that are being designed”.

Students' answers to the open-ended question about their own definition of engineering design were compared to the previously referenced definition of engineering design. A single rater (second author) rated all 44 responses on a four-point scale, with $4=$ excellent, $3=$ very good, 2 = satisfactory, and 1 = poor. The responses were disconnected from student data and had been randomly shuffled with the aid of MATLAB's randperm function so the rater was evaluating the responses in a blinded manner with respect to timing of the question (week 1 vs week 15) and to the particular student.

The results at the start and at the end of the course are shown in Figure 1. 


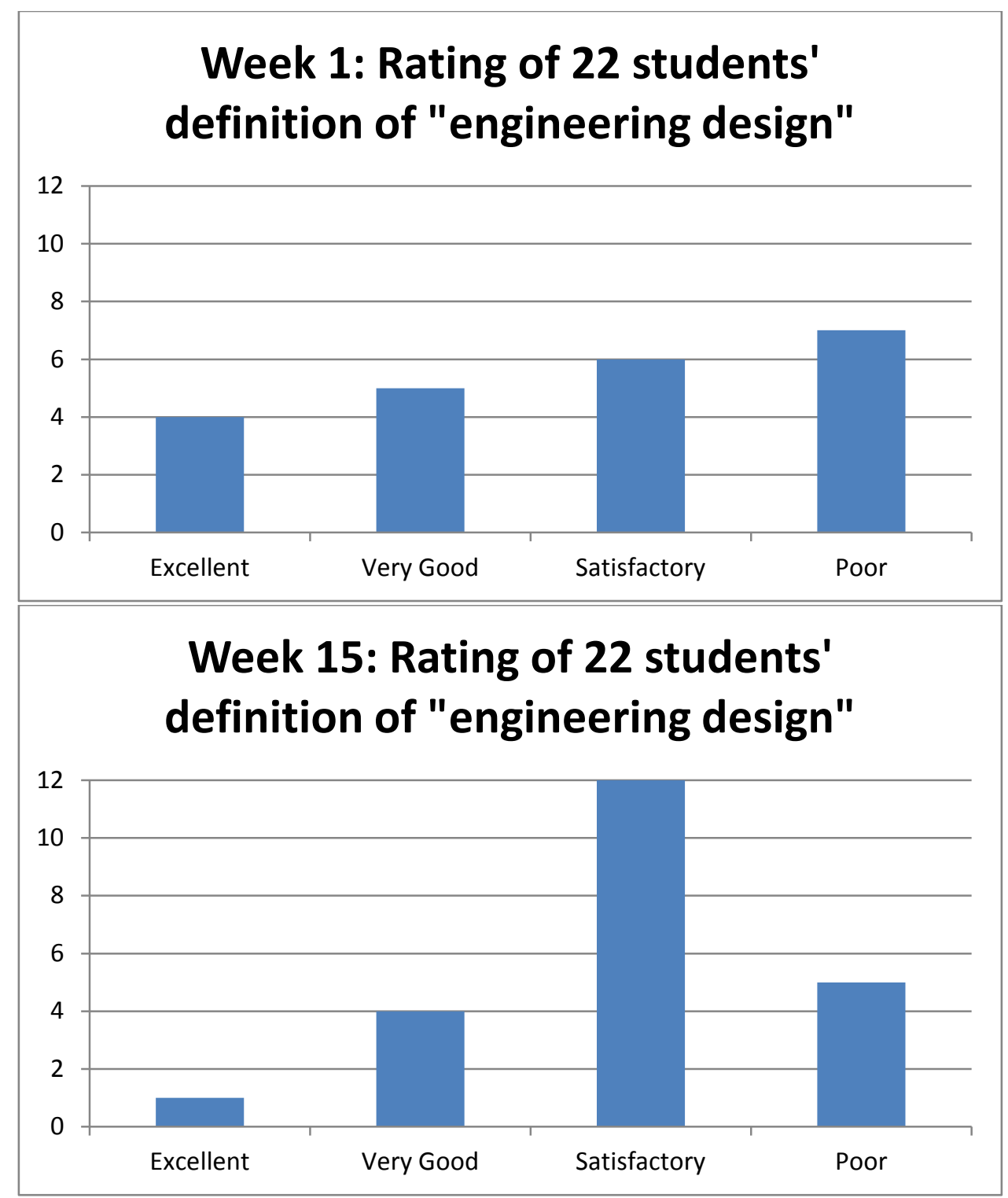

Figure 1: Ratings of the students' definitions of Engineering Design at start and end of the fifteen week course

A paired t-test was performed to determine if the student's perception of engineering design changed during the fifteen week semester of the solid modeling course. The mean change in the rating of their definition $(\mathrm{M}=-0.23, \mathrm{SD}=1.15, \mathrm{~N}=22)$ was NOT significantly greater than zero (and actually went in the opposite direction as presumed). Paired t-Test summary data show that the $t$ statistic $t(21)=0.93$ and the two-tail $p=0.37$. Thus ratings of this open ended question do not appear to be capable of measuring any real change in engineering design over the 15 week semester. 
The only bright side is that the number of poor responses dropped from 7 to 5 (32\% to 23\%) during the fifteen week semester. In a non-blind analysis of the responses, it seems that students in the fifteenth week had other priorities than putting a lot of thought into a survey. Nine of 22 students submitted a weaker definition at the end of the course than at the beginning. Some students clearly put more thought into the week 1 survey. In addition, there is an art in reducing one or two sentences into an integer. It is difficult to develop a system so that two raters come to the same conclusion. That is why we had the same rater rate all responses on the same day. But even a single rater will rate things slightly differently day-to-day when the criteria is not ironclad.

The results presented in Figure 1 leave room for improvement but it must be noted that engineering design was not formally taught in this course. Instead students learned about design by producing 3D solid models from 2D drawings, by reverse engineering physical products into 3D solid models, and by producing 2D drawings for manufacturing.

Survey item 3: Students were presented with nine statements about design. For each of the nine design statements, respondents were given five choices, ranging from "Strongly Disagree" to "Strongly Agree". Results are shown in Figure 2. At both sample points, there was very low agreement with the statements "Good designers get it right the first time", "Good designers have intrinsic design ability", and "Design is iterative".

There was high agreement with the statements "Designers use visual representations as a means of reasoning that gives rise to ideas and helps bring about the creation of form in design", "Visual representations are primarily used to communicate the final design to a teammate or the client", "Design is as much a matter of finding problems as it is of solving them", "Design is a highly complex and sophisticated skill. It is not a mystical ability given only to those with deep, profound powers", "Creativity is integral to design, and in every design project creativity can be found", and "Design, in itself, is a learning activity where a designer continuously refines and expands their knowledge of design". 
Below are a number of statements about design. In the list below, please indicate the extent to which you agree with the statement provided.
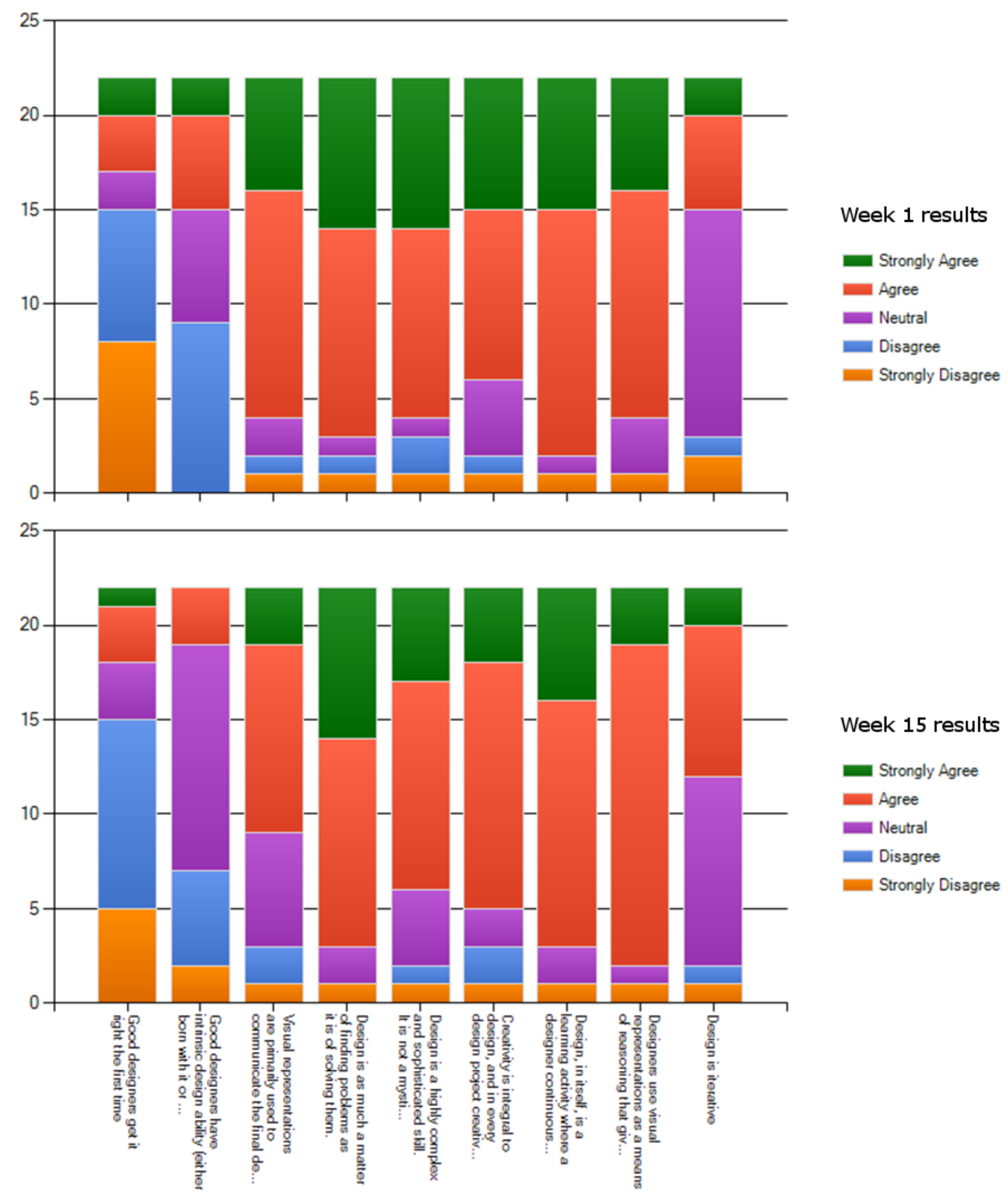

Figure 2: Perceptions of statements related to design. Refer to survey for complete list of statements. 
In Survey item 4, students were asked to rate their perceptions of the value of five items to their career goals. The five items were coincidentally the primary learning outcomes from the course's syllabus. Students considered all outcomes to be at less important to their career goals as time progressed in comparing week 15 results to week 1 results (Figure 3).

Rate your perception of the value of these solid modeling items to your career goals

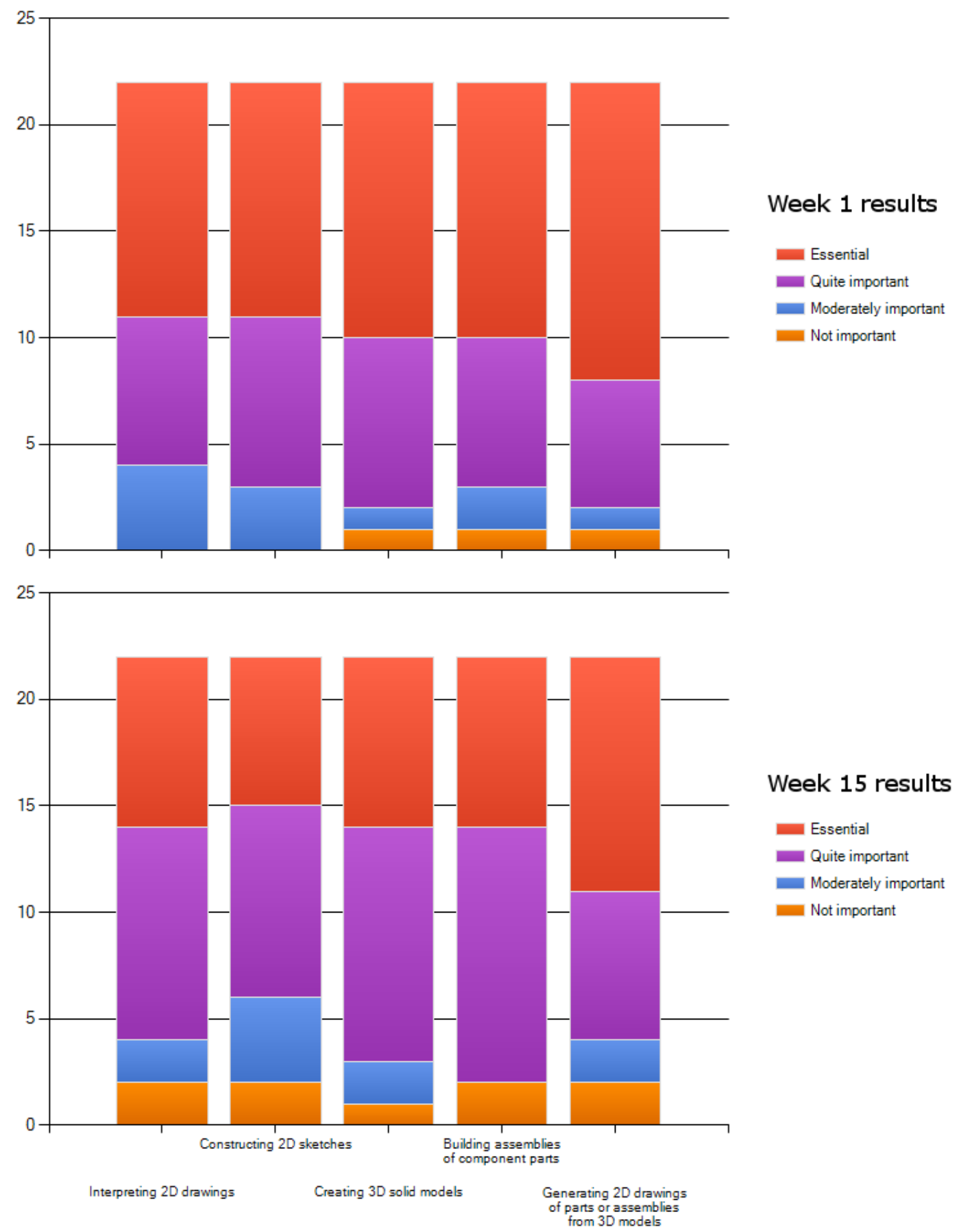

Figure 3: Perceptions of course learning outcomes to career goals. 
In survey item 5, we were interested in the activities that have very low or very high value in solid modeling. Results are presented in Figure 4.

At week 1, the three most strongly identified "most important" activities in solid modeling were Communicating, Planning, and Testing. The three most strongly identified "least important" activities in solid modeling were Making Trade-offs, Abstracting, and Decomposing.

At week 15, the three most strongly identified "most important" activities in solid modeling were Testing, Brainstorming, and Planning. The three most strongly identified "least important" activities in solid modeling were Making Trade-offs, Abstracting, and Decomposing (unchanged from week 1).

Looking at activities that had the most movement during the 15-week course, we compared changes in the number of most or least important selections. The three most active activities were Evaluating (gained 6 least important, shed 2 most important), Iterating (shed 6 least important), and Sketching (shed 5 least important, gained 4 most important). 
Of the activities below, indicate the top six activities that have very low or very high value in solid modeling.

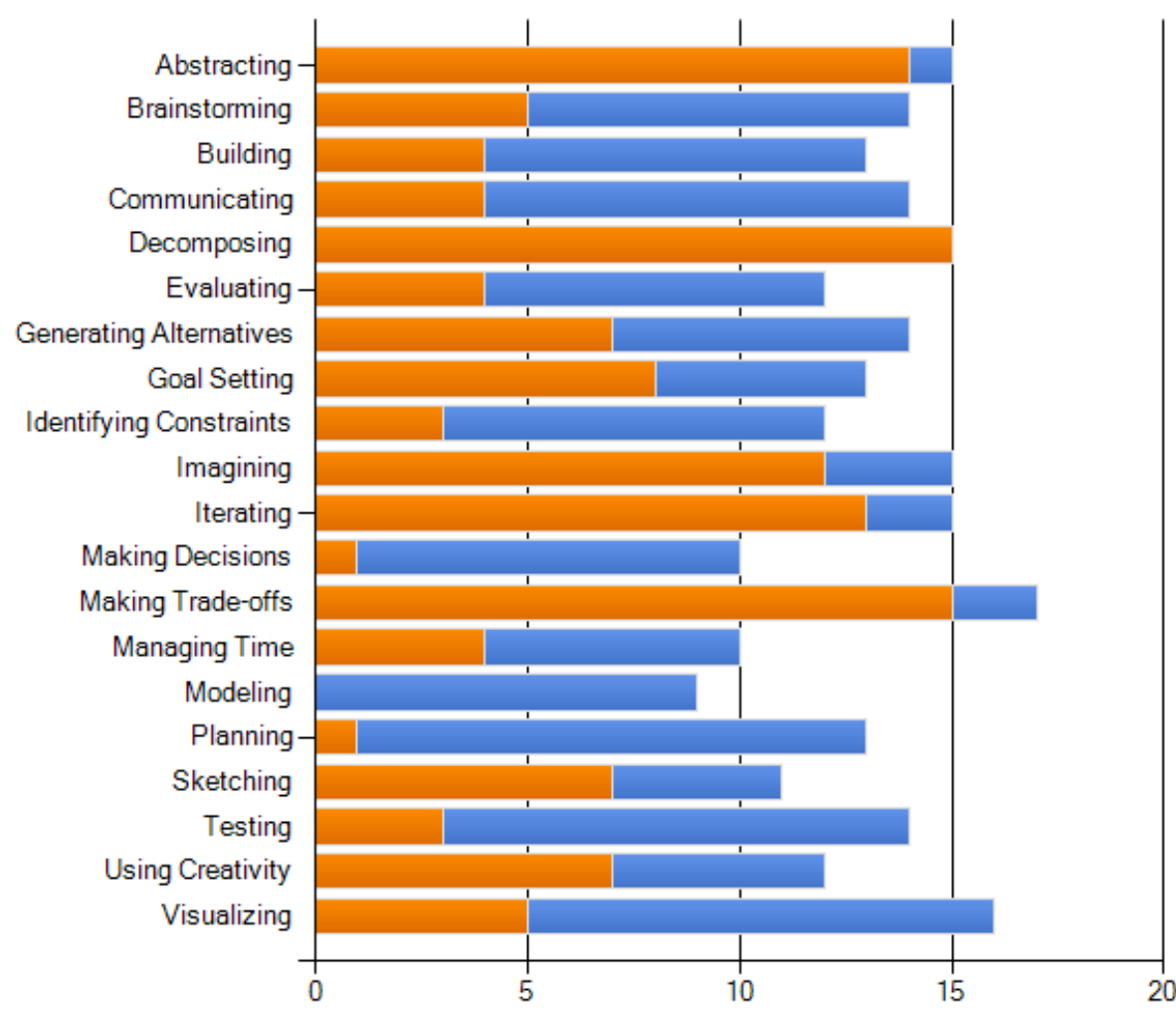

Week 1 results
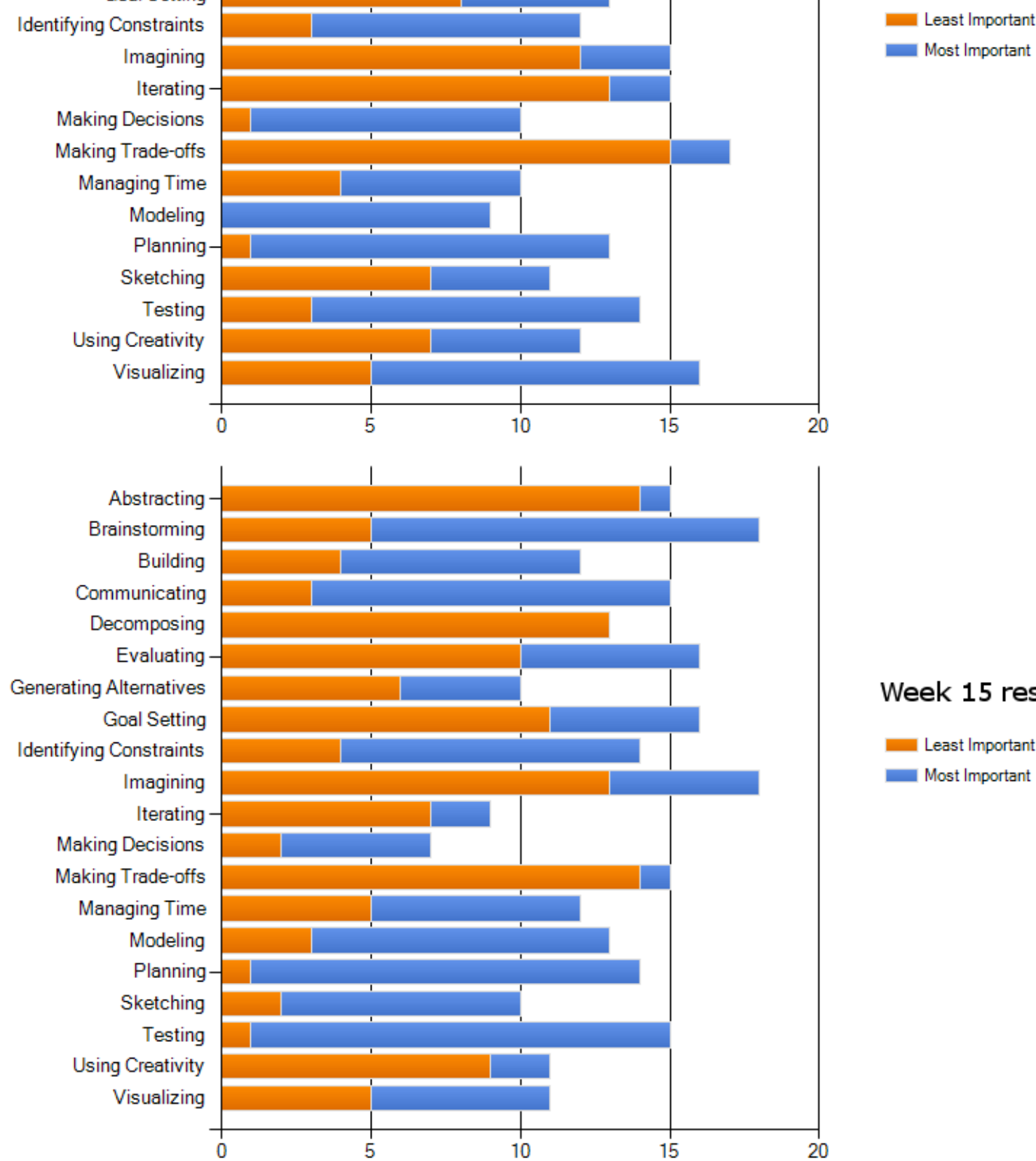

Week 15 results

Least Important

Most Important

Figure 4: Perceptions of activities related to solid modeling. 
Survey item 6: In response to the optional short answer question, "Please name any relevant attributes for successful solid modeling not listed above", 10 responses were received from the 22 students over the two surveys. This response gives us some feedback about ways we could modify the survey for future use. Some responses were related to some of the solid modeling techniques that were emphasized in the course, such as avoiding redundancy of model parameters, and creating simple and changeable models. Other proposed activities were variations of the existing brainstorming and visualization themes.

\section{Discussion and Conclusion}

In Oehrberg's study, 51 undergraduate students in a freshman-level Mechanical Engineering Introductory course were surveyed both before and after the course. The top terms prior to the course were "brainstorming”, “understanding the problem”, and "communicating”. After the course, these remained the top three terms, although order was reversed. In this study, we see that creative activities such as Brainstorming increased in importance. The least important attributes remained unchanged.

In Mosborg's study, communication was a prominent theme, with 12 of the 19 expert engineer's choosing "communicating" as a most important activity. The communication theme was evident in this study too. Communication was the third most often mentioned category when students defined engineering design in their own words. "Communicating” was also in the top three most important solid modeling activities, and it grew in importance during the 15-week course.

The incentive of a one-point bonus to their final grade helped with high survey completion rate. Conducting the survey via the web form had large benefits in that no surveys responses had to be discarded due to failure to follow directions. Also some data analysis can be completed using the built-in tool set.

One of our main priorities as instructors in an engineering program is to foster the design mentality at an early academic age. This will influence the way students' approach engineering problems in general, and design problems in particular. On contrast to the well-defined analysis problems with a single solution, design problems are vaguely defined open-ended problems with multiple possible solutions. More experience with these types of problems can change the way the student approaches problems in the future design courses and professional practice. We have found that solid modeling courses allow us to give the students some real experience with many of the key components of the engineering design process in an environment unencumbered by math and physics. The design of a part or assembly is open-ended in that many solutions can be correct, even though they are quite different.

As instructors, we see a real change in the thought processes as the students progress through the fifteen week semester in solid modeling. However, student supplied definitions on a web survey do not correlate with our observations. Students at the end of the semester just want to complete the survey in as little time as possible, for as big a gain as possible (the extra credit). In the end, the students are actually demonstrating some knowledge about efficiently allocating resources. It is now up to us to find a better way at quantifying the change that we can see quantitatively. 


\section{Bibliography}

1. ABET General Criteria 3. Student Outcomes, http://www.abet.org/DisplayTemplates/DocsHandbook.aspx?id=3143 (last accessed January 2013)

2. Performance Criteria, http://ece.uprm.edu/programs/performanceCri.html (last accessed January 2013)

3. Mosborg, S., Adams, R., Kim, R., Atman, C.J., Turns, J., \& Cardella, M. (2005). Conceptions of the engineering design process: An expert study of advanced practicing professionals. Paper presented at the American Society for Engineering Annual Conference \& Exposition, Portland, OR.

4. Oehlberg, L. and Agogino, A. (2011) Undergraduate Conceptions of the Engineering Design Process: Assessing the Impact of a Human-Centered Design Course, ASEE 2011, June 26 - 29, 2011, Vancouver, BC, Canada

5. SurveyMonkey, http://www.surveymonkey.com (last accessed January 2013)

6. S. J. Kirstukas and N. Al-Masoud (2012) Assessment and Evaluation of ABET Outcomes $C$ and $K$ in Engineering Courses that Utilize Solid Modeling Packages, 2012 ASEE Annual Conference and Exposition, June 10-13, 2012, San Antonio, TX, United States, American Society for Engineering Education.

7. C. L. Dym and P. Little. 2000. Engineering Design: A Project-Based Introduction.. Wiley and Sons, New York.

8. S. Campbell and C.L. Colbeck. 1997. Teaching and assessing engineering design: a review of the research. Paper presented at the American Society for Engineering Education Annual Conference.

9. Gerald F. Smith and Glenn J. Browne. 1993. Conceptual Foundations of Design Problem Solving. IEEE Transactions on Systems, Man, and Cybernetics, 23(5):1209-1218.

10. Soldan, David L., ENGINEERING DESIGN: WHAT IS IT?, IEEE Potentials, v 7, n 1, p 6-8, Feb 1988.

11. Neeley, W. Lawrence; Sheppard, Sheri; Leifer, Larry; Design is design is design (or is it?): What we say vs. what we do in engineering design education, Conference Proceedings, 2006, 113th Annual ASEE Conference and Exposition, June 18-21, 2006.

12. What is engineering design, http://deseng.ryerson.ca/xiki/Learning/Main:What_is_engineering_design (last accessed January 2013)

13. Moodle, version 1.9 (2007) http://moodle.org (last accessed January 2013) 


\section{Appendix A: Web-based Questionnaire}

\section{Solid Modeling Survey}

\section{\begin{tabular}{|l|l|}
\hline $\mathbf{5 0} \%$ \\
\hline
\end{tabular}}

This survey is part of an assessment and evaluation scheme which focuses on the ability of students to design a system or component and to use modern engineering tools necessary for successful engineering practice (key ABET learning outcomes).

There are no right or wrong answers, I just want honest opinions.

For participating in both surveys at the start and end of semester, I will add one point to your final grade.

\section{*1. Name}

(needed so you can be awarded the one-point bonus)

*2. In your own words, how to you define "engineering design"?

*3. Below are a number of statements about design. In the list below, please indicate the extent to which you agree with the statement provided.

\begin{tabular}{|c|c|c|c|c|c|}
\hline & Strongly Disagree & Disagree & Neutral & Agree & Strongly Agree \\
\hline $\begin{array}{l}\text { Good designers get it right the } \\
\text { first time }\end{array}$ & $\mathrm{O}$ & $\Omega$ & 0 & 0 & 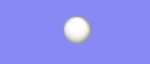 \\
\hline $\begin{array}{l}\text { Good designers have intrinsic } \\
\text { design ability (either born with it } \\
\text { or not) }\end{array}$ & & & & & \\
\hline $\begin{array}{l}\text { Visual representations are } \\
\text { primarily used to communicate } \\
\text { the final design to a teammate or } \\
\text { the client. }\end{array}$ & & & & & \\
\hline $\begin{array}{l}\text { Design is as much a matter of } \\
\text { finding problems as it is of solving } \\
\text { them. }\end{array}$ & C & & O & & \\
\hline $\begin{array}{l}\text { Design is a highly complex and } \\
\text { sophisticated skill. It is not a } \\
\text { mystical ability given only to } \\
\text { those with deep, profound } \\
\text { powers. }\end{array}$ & & & $v$ & & \\
\hline $\begin{array}{l}\text { Creativity is integral to design, } \\
\text { and in every design project } \\
\text { creativity can be found. }\end{array}$ & & & 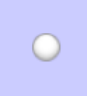 & & \\
\hline $\begin{array}{l}\text { Design, in itself, is a learning } \\
\text { activity where a designer } \\
\text { continuously refines and expands } \\
\text { their knowledge of design. }\end{array}$ & & & & & \\
\hline $\begin{array}{l}\text { Designers use visual } \\
\text { representations as a means of } \\
\text { reasoning that gives rise to ideas } \\
\text { and helps bring about the } \\
\text { creation of form in design. }\end{array}$ & 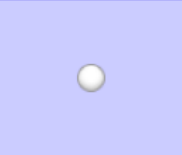 & D & O & & \\
\hline Design is iterative & O & O & $\mathrm{O}$ & O & 0 \\
\hline
\end{tabular}




\section{Solid Modeling Activities}

*4. Rate your perception of the value of these solid modeling items to your career goals

Interpreting 2D drawings
Constructing 2D sketches
Creating 3D solid models
Building assemblies of
component parts
$\begin{aligned} & \text { Generating 2D drawings of parts } \\ & \text { or assemblies from 3D models }\end{aligned}$

*5. Of the activities below, indicate the top six activities that have very low or very high value in solid modeling. (When you finish, there should be SIX marks in each column.)

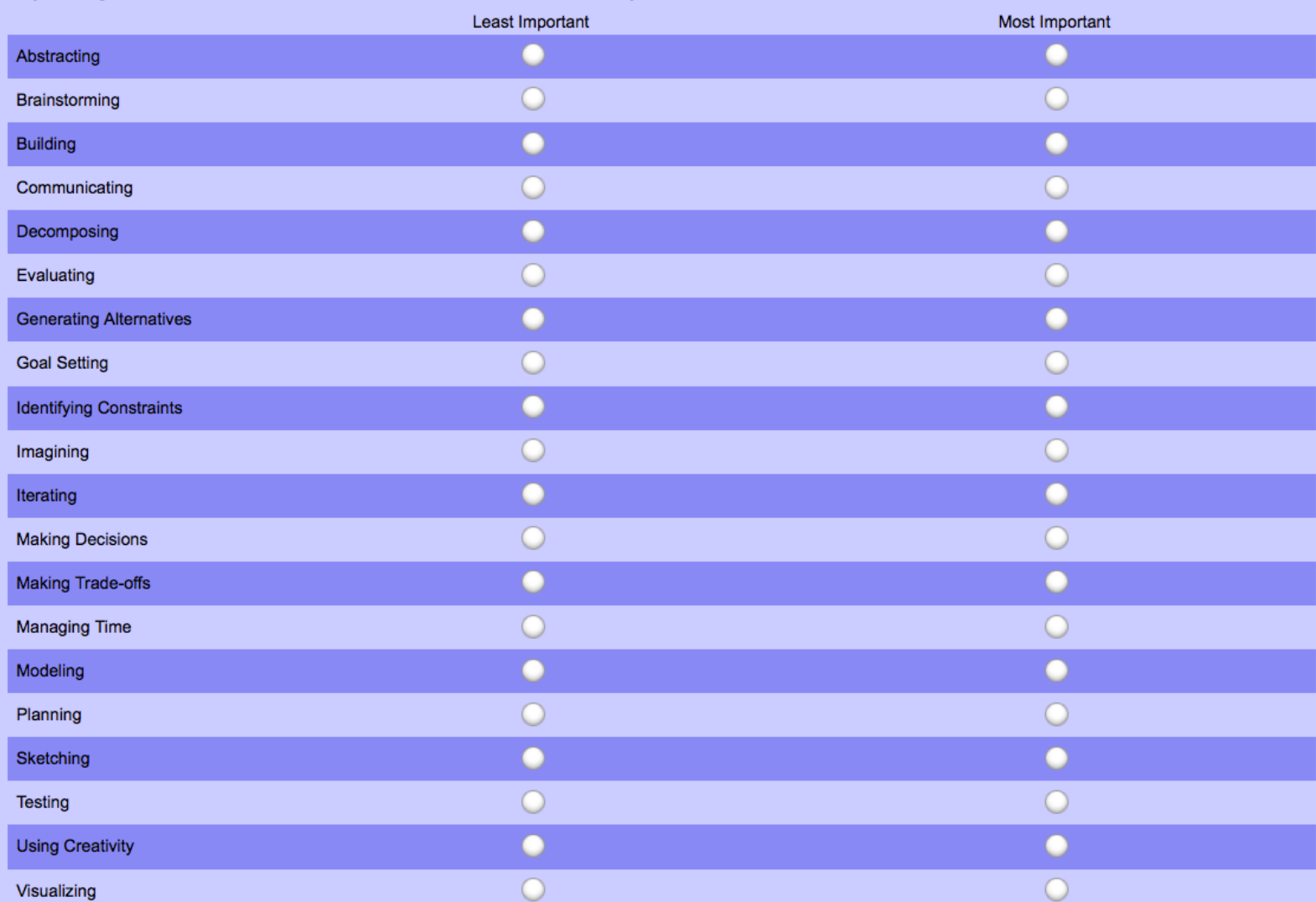

6. Please name any relevant attributes for successful solid modeling not listed above. 